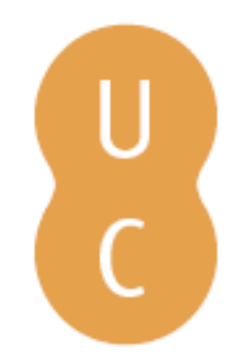

\title{
nommalina
}

\section{Memórias da alimentação e fatos da imigração de luso-brasileiros moradores de uma cidade do sul do Brasil}

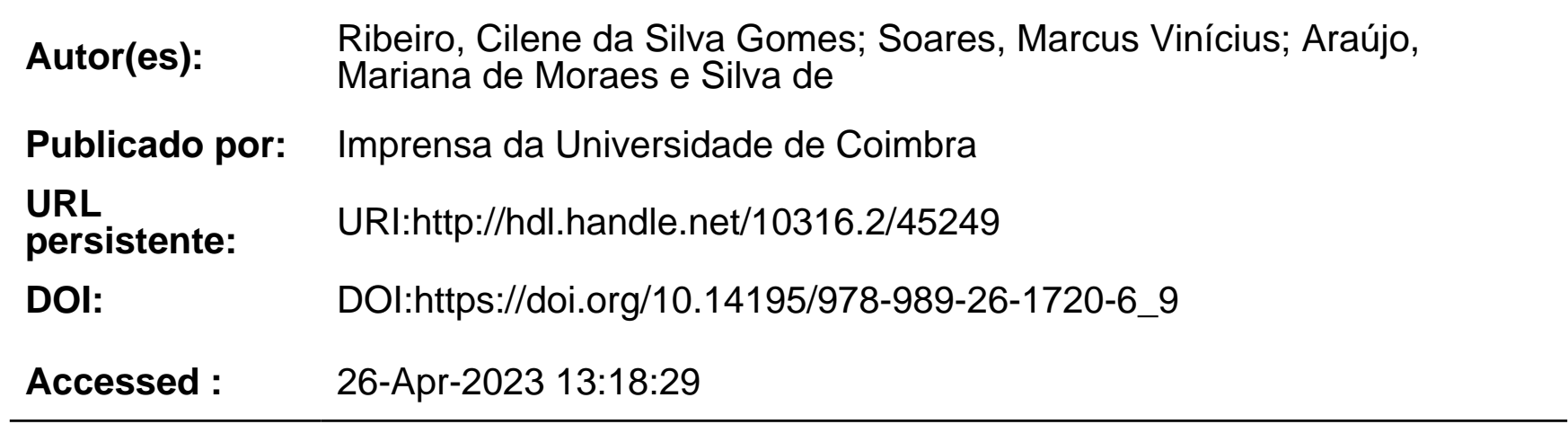

A navegação consulta e descarregamento dos títulos inseridos nas Bibliotecas Digitais UC Digitalis, UC Pombalina e UC Impactum, pressupõem a aceitação plena e sem reservas dos Termos e Condições de Uso destas Bibliotecas Digitais, disponíveis em https://digitalis.uc.pt/pt-pt/termos.

Conforme exposto nos referidos Termos e Condições de Uso, o descarregamento de títulos de acesso restrito requer uma licença válida de autorização devendo o utilizador aceder ao(s) documento(s) a partir de um endereço de IP da instituição detentora da supramencionada licença.

Ao utilizador é apenas permitido o descarregamento para uso pessoal, pelo que o emprego do(s) título(s) descarregado(s) para outro fim, designadamente comercial, carece de autorização do respetivo autor ou editor da obra.

Na medida em que todas as obras da UC Digitalis se encontram protegidas pelo Código do Direito de Autor e Direitos Conexos e demais legislação aplicável, toda a cópia, parcial ou total, deste documento, nos casos em que é legalmente admitida, deverá conter ou fazer-se acompanhar por este aviso.

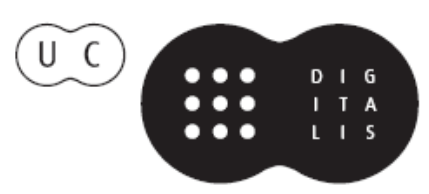


Carmen Soares

\section{Cilene da Silva Gomes Ribeiro}

\section{(coords.)}

MESAS

\section{ALIMENTAÇÃ O, SAÚDE \& CULTURA}

\section{IU LUO-BRASILEIRAS}

\section{VOLUME II}

IMPRENSA DA UNIVERSIDADE DE COIMBRA

COIMBRA UNIVERSITY PRESS

PUCPRESS 


\title{
Memórias da alimentação E Fatos da IMIGRAÇÃO DE LUSO-BRASILEIROS MORADORES \\ DE UMA CIDADE DO SUL DO BRASIL
}

\author{
(Food memories and facts of portuguese-brazilian \\ immigration in Curitiba)
}

\author{
Cilene da Silva Gomes Ribeiro \\ Pontifícia Universidade Católica do Paraná \\ Projeto Diaita: Património Alimentar da Lusofonia \\ CILENE.SILVA@PUCPR.BR \\ Marcus Vinícius Soares \\ MARVIN.SOARESOI@GMAIL.COM \\ Mariana de Moraes e Silva de Araújo \\ MARIANA.ARAUJOGASTRONOMIA@GMAIL.COM
}

Resumo: Encantados pela junção de gastronomia e história, e com a intenção de aprofundamento neste âmbito, o presente trabalho traz a temática da história e lembrança da alimentação, enfocando um grupo específico de portugueses que residem atualmente em Curitiba, cidade pertencente à região Sul do Brasil. A investigação se deu através de relatos orais com portugueses de primeira geração, que emigraram em meados das décadas de 1950 e 1960, resultando em uma pequena viagem pelo tempo e por lembranças recheadas de saudade.

Plavras-Chave: Memórias alimentares, portugueses, imigração.

Aвstract: Delighted by the addition of gastronomy and history, and with the intention of deepening in this area, this study brings the issue of history and remembrance of food, focusing on a specific group of Portuguese who currently reside in Curitiba, city belonging to the southern region of Brazil. The research was through oral accounts with first-generation portugueses who emigrated in the middle of the 1950s and 1960s decades later was made the crossing with other sources, resulting in a small journey through time and stuffed memories of longing.

Keywords: Food memories, Portuguese citizens, immigration. 
O termo luso-brasileiro é empregado para denominar tudo o que é relativo ou pertencente a Portugal e ao Brasil. São chamados luso-brasileiros os indivíduos de origem portuguesa e brasileira, sejam eles natos em qualquer dos países ${ }^{1}$.

A população de portugueses no Brasil, segundo o Censo Demográfico Brasileiro de 2000, era de 213.203 indivíduos, mas é calculada entre 500.000 e 700.000 pelos Serviços do Ministério dos Negócios Estrangeiros Português, em coerência inclusive com o total das inscrições consulares registradas. No Paraná, estima-se que existam cerca de 6.270 indivíduos nacionais portugueses, segundo a Embaixada de Portugal no Brasil, pautada em dados do Departamento de Polícia Federal².

A imigração e colonização de portugueses no Brasil tem se dado desde os primórdios da história brasileira, constituindo mais de cinco séculos de interação e contribuindo significativamente para a construção da identidade nacional deste território. A imigração portuguesa contribuiu de tal forma para o desenvolvimento da nova sociedade brasileira que por muito tempo foi identificada como o novo Portugal ${ }^{3}$.

Embora a História do Brasil seja muito anterior à chegada dos portugueses, em função dos registros destas épocas serem tão rudimentares, quase sempre se parte do seu descobrimento nos fins do século XV e início do século XVI, período em que Portugal dominava o cenário das navegações e descobrimentos. Em busca de um novo caminho para as Índias, com objetivo de conseguir especiarias, os navegadores portugueses desembarcaram no Brasil e aqui se estabeleceram de forma ampla e plena, influenciando no desenvolvimento urbano, nos mercados, na política, na economia, na religião, na gastronomia, na cultura e nos costumes ${ }^{4}$.

O português trouxe ao Brasil alimentos do continente europeu e nos apresentou as técnicas culinárias e de conservação dos alimentos. Trouxe utensílios de plantio e de produção, disseminando novas culturas alimentares e formas de comer. Mas, também fez intercâmbios alimentares no torna-viagem, levando para a terrinha ${ }^{5}$ muitas matérias-primas de origem americana antes desconhecidas ou pouco usadas. Pode-se afirmar que a participação portuguesa na culinária e na gastronomia brasileira se deu tanto no usufruto dos produtos, quanto na inserção e modificação de técnicas culinárias ${ }^{6}$.

Fato é que o alimento é essencial para a sobrevivência dos seres, fazendo com que a busca por algo para comer seja a razão pela qual o homem trabalha, migra e luta desde a Pré-História. Evidências deixadas pelo caminho

\footnotetext{
Rocha, Pires 2001: 381.

Embaixada de Portugal no Brasil 2015.

Scott 2010.

Consiglieri, Abel 2001: 16-19; Franco 2010.

Forma afetiva utilizada pelos portugueses para se referir à terra natal.

Consiglieri, Abel 2001: 16-19.
} 
através dos anos, permitem que pesquisadores passem a entender em que contextos as civilizações anteriores se situavam, como se organizavam, do que careciam e principalmente do que se alimentavam acarretando em grandes contribuições para a formação e relato da história. No caso dos navegantes portugueses, a alimentação e os alimentos foram grandes protagonistas nas buscas e excursões ao redor do mundo. Alimentos sempre foram símbolos de poder e obtê-los e dominar sua produção ou comércio era visto como uma demonstração de riqueza e de dominação de mercados.

Os hábitos estão em constante transformação, independentemente de sua época ou localidade. O tempo todo podem surgir barreiras que irão desencadear rupturas nos padrões utilizados anteriormente, resultando em mudanças, adaptações, sincretismos que daí em diante tornar-se-ão um novo processo, um novo hábito, incorporando-se aos costumes, mas sujeitos à uma nova alteração. Por isso, de acordo com Franco ${ }^{7}$, é sempre possível encontrar nas culinárias, vestígios de trocas culturais entre diferentes povos.

O português deixou marcas que transpassaram séculos, perpetuando ancestralidade e traços de etnicidade a todos os brasileiros nas mais diversas conjunturas, tendo decididamente, assinalado nossa alimentação. Alguns autores renomados da história da alimentação retrataram este intercâmbio alimentar, à exemplo do norteador de diversas pesquisas neste âmbito, Luís da Câmara Cascudo trata da formação da cozinha brasileira a partir da chegada dos portugueses e africanos, no início do século XVI. No capítulo sobre Portugal, intitulado "Ementa Portuguesa", é possível perceber por meio de seu relato (pautado em outros grandes referenciais, a exemplo de Gil Vicente) a maneira como despropositadamente a cozinha que deixou reflexos nos dias atuais, foi se formando ao longo dos séculos passados.

Com isso, é possível concluir a importância da alimentação, ou do alimento, através dos tempos, como fator identitário, ou imprescindível ao estudo da história, uma vez que é característico e pode revelar dados a respeito de uma civilização, ou até mesmo uma família.

A partir desta percepção, a alimentação vem ganhando destaque na elaboração de trabalhos, estejam eles ligados à fatores nutricionais, históricos ou psicossociais, e é neste contexto que se insere este estudo, que visa tratar das memórias alimentares e entender as motivações da imigração, relacionadas à alimentação, de luso-brasileiros que residem atualmente em Curitiba, com o objetivo de identificar fatores influenciadores da alimentação, revelando

\footnotetext{
7 Franco 2010.

8 Cascudo 2004.
} 
hábitos atuais e memórias de portugueses de primeira geração, imigrantes das décadas de 1950 e 1960.

Este estudo, pois, se iniciou com o levantamento de possíveis entrevistados, através da Sociedade Portuguesa Primeiro de Dezembro (SPPD), instituição que visa a aproximação e promoção de atividades relacionadas a comunidade luso-brasileira, situada no centro de Curitiba, no estado do Paraná. A pesquisa foi desenvolvida alicerçada por relatos orais, através da metodologia da história oral, com 14 portugueses de primeira geração, de faixa etária superior a 54 anos, e uma entrevista com descendente de portugueses, todos moradores do município de Curitiba, sendo estes relatos os ingredientes necessários para emulsificar este estudo.

\section{i. Portugueses e o Paraná: uma história ao acaso?}

No Paraná, os estudos de Santos ${ }^{9}$ vêm acarretar em grande coletânea de trabalhos em diversos âmbitos da História da Alimentação, contribuindo significativamente para a construção e pesquisa de novos trabalhos. Em seu livro "História da alimentação no Paraná", Santos ${ }^{10}$ enfoca o período da formação do estado, que se dará principalmente na segunda metade do século XIX, com a emancipação da Quinta Comarca de São Paulo, que passaria à então Província do Paraná, dando destaque para as ocorrências em torno da cidade de Curityba - na grafia da época - que crescia urbanamente concomitante à província.

No período imediatamente anterior à emancipação, o principal fator contribuinte para que esta se concretizasse fora o grande crescimento da indústria ervateira no Paraná, que na década de 1840 exportava grandes números através do porto de Paranaguá. No entanto, neste mesmo período, Santa Catarina e Rio Grande do Sul passam a exercer a mesma atividade, alcançando maior qualidade nos seus produtos, fazendo com que esta prática viesse a definhar, assim como previra o primeiro presidente da então província, Zacarias de Góes e Vasconcelos ${ }^{11}$.

Nesta segunda metade do século, outros fatores que aqui se mostram interessantes, são apontados como importantes e até mesmo determinantes para os rumos tomados pelo estado, a exemplo da abolição da escravatura, que levará a necessidade de outro tipo de mão de obra em substituição a esta.

Segundo Santos ${ }^{12}$ :

\footnotetext{
9 Carlos Roberto Antunes dos Santos é expoente nos estudos da História da Alimentação, tendo orientado diversos trabalhos de doutorado, mestrado e graduação na área.

10 Santos 2007.

11 Santos 2007.

12 Santos 2007: 50.
} 
Memórias da alimentação e fatos da imigração de luso-brasileiros moradores de uma cidade do sul do Brasil

[...] o desempenho da economia brasileira a partir da metade do século XIX é cadenciado por importantes mudanças: a abolição do tráfico de escravos, a criação de um novo regime de terras, o apoio e a vinda de imigrantes, a introdução do trabalho assalariado e a expansão do comércio exterior que permite uma nova dinâmica do comércio interno.

Neste período há a criação de um projeto que visava o futuro da província, sendo sua emergência respaldada pelos diversos problemas da economia que começaram a surgir nesta época. Dentre estes estava a emancipação dos escravos, conforme já citado anteriormente, que elevou o trabalho ao status de atributo básico da dignidade, do esforço reconhecido e de produtor de riquezas, momento em que o Governo Imperial passa então a apoiar e subsidiar a vinda de imigrantes, dando preferência aos "laboriosos e morigerados", reafirmando a ideia de que o binômio colonização dos imigrantes e emancipação dos escravos constitui fatores importantes para o desenvolvimento do Paraná. Desejavam, sobretudo, os imigrantes europeus para que trouxessem hábitos civilizados e uma nova ética de trabalho para o país ${ }^{13}$.

Segundo Nadalin ${ }^{14}$ :

[...] o imigrante europeu era encarado sob uma concepção romântica, e acreditava-se que ele seria capaz de recriar uma "civilização camponesa à maneira da Europa”, em oposição à "sociedade maculada pelos vícios de origem brasileiros [sic].

Por esse motivo, alguns imigrantes de nacionalidades específicas, vistas como sinônimo de trabalho e organização, eram mais desejados do que outros. Em geral, esses grupos tiveram sua imigração dirigida para terras previamente definidas e receberam algumas facilidades para efetuar o pagamento das mesmas. Além disso, muitos imigrantes dessas nacionalidades vieram para o Paraná reimigrando de outros estados, principalmente Santa Catarina ${ }^{15}$.

Ou seja, foi através do incentivo à imigração que se constituiu a formação do nosso estado, fazendo com que qualquer busca no passado destas terras passe obrigatoriamente por um estudo etnográfico.

No entanto, no que tange a presença e vinda dos portugueses para os estados brasileiros, principalmente neste período, há dificuldades quanto a expressão dos números, explicada por Fiamoncini ${ }^{16}$ e da mesma forma

\footnotetext{
13 Santos 2007.

$14 \quad$ Nadalini 2001 apud Fiamoncini 2008: 23.

15 Fiamoncini 2008: 23.

16 Fiamoncini 2008: 17.
} 
por Passos ${ }^{17}$ como sendo em razão da demora da historiografia perceber os imigrantes portugueses como imigrantes, e não mais como colonizadores.

A análise das tabelas expostas nos estudos de Santos ${ }^{18}$, oriundas dos Relatórios do presidente Lamenha Lins, no ano de 1875, ano em que é posto em prática o plano de incentivo à colonização, ajudam a confirmar esta ideia, uma vez que os imigrantes portugueses são citados em apenas uma delas. $\mathrm{O}$ número de portugueses, perdia significativamente para o número de italianos à época, que aí representavam o maior número dos atraídos pela nova política da província, em busca de trabalho.

Alguns grupos, como no caso dos germânicos e italianos, receberam subsídios do governo para sua instalação, neste período marcado por uma maior demanda de mão-de-obra, o que, no entanto, não se aplicou à política imigratória portuguesa. Apesar disso, o Brasil, ainda constituía um destino desejado pelos portugueses, não somente pelos salários mais altos com relação aos praticados em Portugal, mas por permanecer no seu imaginário como uma terra de abundância e oportunidades ${ }^{19}$.

Para Passos ${ }^{20}$, "o fato de dominarem a língua do país de acolhimento lhes conferia certa autonomia e vantagem em relação aos demais imigrantes", o que coincide com a ideia explicitada por Pereira ${ }^{21}$ de que fatores como a língua e cultura alimentar similares eram atrativos por passar a imagem de que sua integração na sociedade de acolhimento seria facilitada.

Além disso, cidades brasileiras passavam por um momento de ascensão econômica, que também pode ter servido de motivação à vinda destes imigrantes, conforme expõe Boschilia ${ }^{22}$ :

[...] o crescente processo de urbanização das cidades brasileiras, associado ao crescimento econômico e ao avanço dos meios de comunicação, motivava o deslocamento desse numeroso e diversificado contingente populacional.

Boschilia ${ }^{23}$, em seu artigo: " $A$ procura de um novo destino: Portugueses no Paraná da segunda metade do século XIX”, percebendo a dificuldade em encontrar dados a respeito da imigração portuguesa para o estado, faz uma rica pesquisa pautada em dados que conseguem dar nome, idade, naturalidade e, finalmente, identidade a estes imigrantes que chegavam no Paraná em busca de melhores

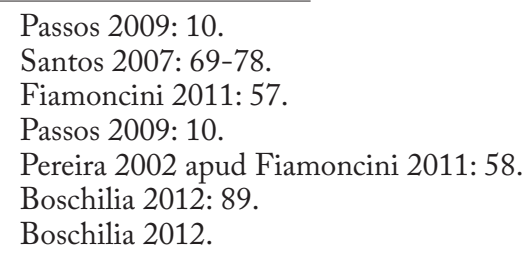


condições de vida, aproveitando-se de um momento de expansão do estado enquanto crises abalavam a economia do seu país. A autora dá destaque para a construção da ferrovia no Paraná, num período imediatamente posterior a emancipação do estado, que começava a tomar aspectos urbanos. A indústria ervateira dominava principalmente a região de Curitiba, fazendo com que esta fosse a região que primeiro iria urbanizar-se, onde surgiram os primeiros comércios, tornando-se o melhor local para estes imigrantes se estabelecerem.

É importante destacar que grande parte dos portugueses que aqui foram chegando, são categorizados como "reimigrantes", uma vez que muitos partiam de cidades como São Paulo e Rio de Janeiro, onde já desenvolviam alguma atividade ligada ao comércio. $\mathrm{O}$ rápido crescimento do estado, que demandava a necessidade de artigos de consumo como vestuário, alimentação e medicamentos, motivou a vinda destes portugueses, fazendo com que inclusive, muitos aqui estabelecessem comércio, e até sentissem necessidade de chamar os parentes de Portugal para ajudar nas vendas e nos negócios, aumentando ainda mais o interesse nas relações e a atração dos portugueses para o Brasil ${ }^{24}$.

Esse fluxo migratório proveniente de outros estados, assim como de outras cidades do Paraná, contribuiu de certa forma para o processo de metropolização de Curitiba, que ocorreu de maneira acelerada em um curto espaço de tempo. Em meados de 1940, é instituído um plano com o intuito de traçar diretrizes para a urbanização da cidade, intitulado como Plano Agache, em referência ao urbanista Alfredo Agache, criador do plano diretor oriundo da construção de Goiânia. Na década de 1950, já era perceptível a grande transformação que ocorrera, fazendo com que Curitiba alterasse o status de uma cidade modesta para uma verdadeira capital. Este período também é marcado por fatores como: o aumento populacional, impulso na geração de energia, transformações e modernizações trazidas pelos novos planos urbanos ${ }^{25}$. Diz-se do exposto, que o planejamento de Curitiba, entre os anos de 1950 e 1960, acabou por induzir aumento populacional, industrial e comercial, acompanhando os grandes centros urbanos do país ${ }^{26}$.

Trabalhar com a imigração portuguesa para Brasil nas décadas de 1950 e 1960, aos olhos de Paulo 27 é "trabalhar num grande palheiro de agulhas perdidas", uma vez que as instituições, principalmente associativas, de onde poderiam surtir dados relevantes, acabam mantendo uma preocupação primordial com o presente e com os sócios, reduzindo as informações à fichas pessoais com dados de maior importância, como o endereço para envio de cotas a serem pagas. Ao elaborar sua pesquisa visando traçar a trajetória da adesão do emigrante ao sa-

\footnotetext{
24 Boschilia 2012: 95.

Ribeiro 2013: 49.

Reichembach 2007: 18.

Paulo 1997: 7.
} 
lazarismo, através da colônia portuguesa radicada no Rio de Janeiro, encontrou dificuldades também devido a Inundação no depósito da Biblioteca Nacional do Rio de Janeiro em 1995, que levou a destruição de arquivos referentes a "Voz de Portugal' principalmente dos períodos de 1945 a 1960.

Tendo em vista que este é o período que aqui pretende-se tratar, e que grande parte dos imigrantes presentes em Curitiba coevos desta imigração mantém a condição de reimigrantes, especialmente advindos do Rio de Janeiro e São Paulo, acabou-se também encontrando dificuldades na busca de informações nas fontes consultadas. Especialmente para o Paraná e Curitiba, os períodos dos quais se tem maiores informações e conteúdo são o final do século XIX e início do século XX, decorrente da formação do estado e povoamento da cidade.

Conforme já citado anteriormente, o Paraná começa a desenvolver sua política imigratória a partir da emancipação da província de São Paulo, em 1853. Com a abolição da escravatura em 1888, a necessidade urgente por substituição de mão de obra faz com que subsídios sejam ofertados para alguns grupos étnicos, cujas características correspondiam ao idealizado pelo governo imperial, a fim de inseri-los na produção agrícola do estado. No entanto, esta prática de subsídio nunca fora dada ao português, que ainda assim demonstrava preferência pelo Brasil, não somente pelos salários mais altos que os praticados em Portugal, mas também pela familiaridade com a língua ${ }^{28}$.

Com os demais grupos étnicos se estabelecendo na produção agrícola, o português encontrou alento na exploração do comércio, alicerçada, segundo Lobo $^{29}$ por alguma experiência prévia em relação ao trabalho de manufatura, que garantiu algumas vantagens sobre os brasileiros recém-libertos ou mestiços urbanos, no que se refere ao nascente mercado de trabalho capitalista brasileiro.

Fiamoncini ${ }^{30}$ ao tratar da inserção do português no comércio em Curitiba, completa:

[...] enquanto os demais grupos imigrantes tinham como principal ocupação produzir gêneros agrícolas de subsistência, os portugueses ocupavam-se em fornecer para eles os produtos industrializados que necessitavam. Já familiarizados com o comércio em outros locais do Brasil, encontravam aqui menor concorrência do que em São Paulo e Rio de Janeiro.

Através da análise dos censos de 1872, 1900 e 1920, pode-se inferir que os portugueses que imigraram principalmente para Curitiba e Paranaguá, eram, em sua maioria, oriundos do norte de Portugal, sendo o número de

\footnotetext{
28 Fiamoncini 2008: 20.

29 Apud Fiamoncini 2008: 21.

30 Fiamoncini 2008: 24.
} 
homens superior ao de mulheres, e tendo estas características observadas como comuns aos portugueses dos demais estados brasileiros ${ }^{31}$.

\section{A imigração no século XX: motivações e interesses}

No tocante ao século XX, em Portugal, alguns acontecimentos guardam certa relevância: a queda da monarquia e a implantação da República (5 de outubro de 1910), uma rebelião militar (1926) levando a uma ditadura (19261974), o restabelecimento da democracia parlamentar seguido da revolução de 25 de Abril de 1974. A instabilidade política que caracterizou Portugal nas primeiras décadas do século XX trouxe dificuldades econômicas para o país. Em um cenário de insatisfação política, social e econômica, a imigração é intensificada, principalmente na década de $1960^{32}$.

Para melhor compreender e alicerçar as razões que podem ter motivado portugueses a saírem do seu país, buscou-se entender o encadeamento de Portugal no período imediatamente anterior a sua chegada no Brasil: as décadas antecedentes às de 1950 e 1960, correspondentes ao período da infância dos entrevistados e grupo de foco.

Segundo $\mathrm{Scott}^{33}$, mais de meio milhão de portugueses emigraram entre os anos de 1886 e 1960. Número irrisório se comparado ao outro meio milhão que emigrou no curto período correspondente a 1960 e 1970, sendo estes valores pertinentes somente à emigração legal, estimando-se que mais trezentos mil portugueses teriam deixado Portugal clandestinamente nestas duas décadas referidas, acarretando à Portugal, a perda de $20 \%$ de sua população.

Revela-se, portanto, de extrema importância para o que se quer tratar, o período que compreende a Segunda Guerra Mundial (1939-1945), bem como o pós-guerra, visto que este momento vivido pela nação global, afetou até mesmo os países que não participaram ativamente do conflito, a exemplo de Portugal.

Scott ${ }^{34}$ relata que com a eclosão da Segunda Guerra Mundial houve uma queda no movimento emigratório português, mas que no pós-guerra voltou a aumentar paulatinamente, atingindo seu ápice em 1966. Encontra-se uma explicação para esta queda, nos textos de Pasckes ${ }^{35}$, que indica através de dados estatísticos sobre a mão-de-obra portuguesa no Brasil, que no período que vai de 1934 a 1960 o valor correspondente era de $18,30 \%$, enquanto que para os 49 anos precedentes (1884-1933), este valor era de 68,39\%. Pasckes atenta, ainda, para o fato desta

\footnotetext{
Fiamoncini 2008: 24.

Morais et al. 2012: 8-18.

Scott 2010: 148.

Scott 2010: 148.

Pasckes 1991: 81-93.
} 
diminuição ocorrer conseguinte ao início do período de Salazar - nomeado Ministro das Finanças de Portugal em 1928, passando a chefe supremo do Governo até 1968 -, apontando como causa a política de emprego que se estabeleceu através dos Planos de Fomento instituídos em sua economia corporativista.

$\mathrm{O}$ artigo de Isabel Drumond Braga ${ }^{36}$, mostrou-se importante fonte de informações acerca deste período, principalmente pelo que trata sobre alimentação, ou neste caso, sobre a carente alimentação em Portugal, uma vez que retrata a escassez de alguns alimentos no país. Segundo Braga ${ }^{37}$ :

em plena II Guerra Mundial, o racionamento e a falta generalizada de alguns produtos alimentares era bastante evidente mesmo para Estados como Portugal, que não se envolveram diretamente [sic] no conflito. $\mathrm{O}$ país não era auto-suficiente em termos alimentares, dependia do abastecimento exterior de muito géneros, provenientes de países beligerantes e ocupados, conhecia uma permanente irregularidade de fornecimentos, agravada pelos problemas que a guerra provocava ao nível da produção e do transporte e a inflação aumentava.

Para a autora, o conflito bélico apenas tornou mais evidente as vulnerabilidades estruturais da economia portuguesa, que apesar de resultados promissores dados pela "Campanha do Trigo" na década de 30, quando houve um aumento da produção agrícola, o setor mostrou-se ineficiente frente ao novo cenário político, e veio a definhar concomitante ao início da II Guerra Mundial.

$\mathrm{Braga}^{38}$ ainda destaca que jornais e revistas da época testemunharam o momento triste no qual a economia portuguesa se encontrava, bem como anedotas que, no entanto, não desdramatizavam a situação, como no caso do que fora publicado em O Século Ilustrado, a 4 de julho de 1942: “-Vês aquele tipo? É um felizardo. / - Felizardo, porquê? / - Porque tem uma nódoa de azeite no casacão”.

A tendência neste momento de tensão, é que alguns fatores demonstrem "efeito dominó", fazendo com que a falta de um elemento, leve a carência de outro. Ainda do texto de Braga ${ }^{39}$ extraímos o excerto:

o combustível era pouco e as embarcações pesqueiras ficavam em terra alguns dias levando à falta de peixe e ao aumento do seu preço, ao mesmo tempo que escasseavam igualmente com frequência açúcar, arroz, bacalhau e manteiga.

\footnotetext{
36 Braga 2015.

37 Braga 2015: 5 .

38 Braga 2015: 5 .

39 Braga 2015: 6.
} 
O contexto sombrio e taciturno imposto pela longa ditadura salazarista instalada na década de 1920 também pode ser visto como um dos grandes propulsores à emigração de portugueses para o Brasil na metade do século XX. Segundo $\operatorname{Scott}^{40}$, Portugal padecia de um atraso econômico crônico em relação à Europa além-Pirineus, e os portugueses encontraram na emigração para o Brasil uma alternativa para as agruras da sociedade portuguesa da época.

Apesar de algumas ações iniciais de Salazar terem sido bem vistas pela nação portuguesa, e de seu governo ter se favorecido disso, boa parte da população manteve-se em situações precárias próximas da miséria na maior parte do país, sem acesso a luz e água encanada ${ }^{41}$. Salazar, após ter sido nomeado presidente do Ministério das Finanças, instituiu o Estado Novo e com isso grande parte da população portuguesa sofreu com restrições na economia e falta de oportunidade de emprego ${ }^{42}$.

Salazar impôs ditames que, na visão de muitos, funcionavam como facilitadores na organização social, mas que para outros, não passavam de regras impositivas e reguladoras. Essas imposições causavam medo, muitas vezes confundindo os sentimentos de alguns portugueses, fazendo aumentar o anseio pela emigração. Entre os anos de 1940 e 1960, os portugueses passaram por um período sôfrego e de insegurança, fazendo com que muitos deles concretizassem esse anseio em busca de novas oportunidades.

Salazar tinha tendências fascistas e comandava o governo segundo critérios pré-estabelecidos. Para os portugueses que permaneceram no país foram anos muito difíceis. Diante dessa situação, a população das grandes cidades começou a criar resistência ao seu governo, instalando-se o caos nas ruas. Já nas pequenas cidades o reflexo foi sentido pela escassez e pelo alto valor dos suprimentos que chegavam à estas regiões ${ }^{43}$.

Basicamente, nestas cidades os camponeses tiravam seu sustento do que plantavam, e mesmo com as tais "políticas de emprego", o acesso a ele para quem estava nas menores cidades, era dificultado. No relato do Sr. J.G., 73 anos, proveniente do município de Proença-a-Nova, que diz que à época, "era tudo muito caro, difícil e o ganho era muito pouco", trabalhavam duro na roça, sem registro, sem direito a nada.

\footnotetext{
Scott 2010: 30 .

Ribeiro 2015: 260.

Nogueira 2001.
}

43 Os anos da Ditadura Salazarista 1993 (EBM). Direção de António Rocha, Clarisse Mendes, Laura C. Moreira, Manuel Pires, Manuela Brazão, Maria José Garção, Natália Belchior, Odete Martin. Produção de António Rocha, Laura C. Moreira, Manuel Pires. Realização de Francisco Alves, Ensino Básico Mediatizado, EBM, 1993. Música: “una Casa Portuguesa”, por Amalia Rodrigues. [s.i.]: Cinematografia Portuguesa, 1993, (15 min.), son, color., Disponível em: <https://www.youtube.com/watch?v=ndfWzNEKV7E>. Acesso em: 01 jun. 2015. 
Segundo o Sr. M.A.T.S. ${ }^{44}, 74$ anos, português que emigrou em 1960, proveniente do vilarejo de Gião, da região de Candemil, Amarante, a época de Salazar era paradoxal e em virtude de consequências econômicas, acabou por estimular muitos portugueses a emigrarem para diferentes localidades. Sobre Salazar, relata:

"ele [Salazar] tirou Portugal das dívidas e seus cofres ficaram abarrotados de dinheiro [...] mas por outro lado, não investiu em nada, em nenhuma indústria, em nada e só não passávamos fome porque plantávamos algumas coisas [...] deixou o país paralizado, e não havia emprego para ninguém. As pessoas viviam da agricultura e comiam o que dava em suas terras e só isso. [...] A solução era sair de lá e emigrar para outros locais. [...] Nessa época eu era criança e lembro que nem meu pai falava de Salazar em casa porque tínhamos medo, porque ele mandava prender todo mundo. [...] A luz [elétrica, neste caso] a gente não tinha na aldeia, mas a gente sabia que nas cidades maiores já tinha sim”.

O Sr. M.A.T.S. relata uma época em que recursos eram muito escassos, da mesma forma que o Sr. J.M.P., 86 anos, proveniente da região de Miranda do Douro. A maioria dos pequenos vilarejos rurais eram desprovidos de água encanada e luz elétrica, e por consequência de todas as facilidades geradas e possibilitadas por tais recursos. A vida era feita de práticas simples. A sobrevivência se dava através da manufatura e de ações locais, de pequenas e singelas permutas.

"Na época do verão, nós lá tínhamos um pimentão, uma alface, uma vagem, uma cebola... mas, isso aí era só na época do verão. Depois a gente guardava no inverno para não congelar. [...] $\mathrm{Na}$ geada, guardava embaixo da cama... conversava um pouquinho mais, pra ir comendo no inverno. Essa era nossa vida”. (J.M.P.)

“[...] lá nós éramos em sete irmãos. Meus pais trabalhavam muito, a gente comia, mas não tinha dinheiro para comprar nada. $\mathrm{O}$ governo não nos dava nada, não tinha trabalho para quase ninguém, não tínhamos nada. O povo vivia na miséria. [...] Só ganhávamos dinheiro criando bezerros [vitela] e galinhas e vendendo na feira. Assim a gente conseguia comprar sal, peixes, remédios, ferramentas e roupas. Pra tomar água a gente tinha

44 Por questões éticas, estes indivíduos não serão aqui identificados, sendo indicados, quando referenciados, por siglas, a fim de diferenciar os seus depoimentos. Com o intuito de melhor compreensão do texto, convencionou-se aqui, expor os trechos dos depoimentos escolhidos na forma de recuo, com fonte menor à do texto, entre "aspas duplas", sendo os comentários dos autores nas citações, explícitos [entre colchetes]. [reticências entre colchetes] indicam supressões e, apenas reticências [...] indicam uma pausa no ritmo da fala dos depoentes. A referência do depoimento se dará de duas formas: a) No corpo do texto, sendo neste caso, a citação antecedida de dois pontos; b) Ao final da citação (entre parênteses). A primeira aparição de cada entrevistado no texto, sempre se dará com a inserção da sua idade, região de procedência e, para os casos de segunda geração, esta será assinalada. 
Memórias da alimentação e fatos da imigração de luso-brasileiros moradores de uma cidade do sul do Brasil

que ir pegar na fonte. Pra acender o fogo, a gente tinha que ir tirar a lenha nas terras. [...] Era mesmo uma vida muito difícil”. (M.A.T.S.)

O Sr. A.M.L., 78 anos, há 57 anos no Brasil, proveniente de Castelo Branco, região da Beira Baixa, relatou como era a sua vida na região, nas décadas de 1940 e 1950:

"Vivíamos isolados, sem rádio, sem televisão, sem luz elétrica, sem água
encanada. Não sabíamos de nada. [...] Morávamos lá, criávamos nossos
animais e comíamos o que plantávamos, não tínhamos nada, a miséria
era grande, mas não sabíamos o que existia fora daquele lugar... eu nem
imaginava o que existia fora de lá, mesmo com os meus 20 anos de idade”.

O Sr. A.J.F., 85 anos, também proveniente de Castelo Branco, tendo morado em Lisboa, relatou que mesmo com a ditadura e com a pouca fartura na época, tinha um pouco mais de alimentos disponíveis que os demais entrevistados a partir do momento que foi morar em Lisboa. Mas, no período em que morava na fazenda (no interior) a escassez estava presente:

"Comíamos feijão frade. Lá em Beira Baixa tem muito feijão fradinho. Era feijão de manhã, feijão no almoço e feijão na janta. Sardinha frita, sardinha assada e carne de porco. Meu pai matava dois porcos por ano e como a gente morava em fazenda, alimentávamos com resto de batatas e de abóboras, couves".

Interessante foi que, durante a fala do Sr. A.J.F. houve a interferência de um comentário feito pelo Sr. J.M.P.: "Quem matava dois porcos, naquela época, já estava muito bem de vida. Nós não tínhamos isso na nossa terra”.

Da mesma forma, em entrevista com o Sr. A.L.S, este com 68 anos e há 55 anos no Brasil, se desvela esse universo que associava o trabalho, o medo e a busca pela fartura na época de Salazar:

"Ele [Salazar] não impedia a emigração porque era notório que não havia recursos para todo mundo sobreviver. $\mathrm{Na}$ época em que eu estava lá, meus pais trabalhavam de sol a sol, puxando enxada dia a dia, e o que produziam era apenas para o consumo".

O comentário do Sr. A.L.S. corrobora com citações de Fiamoncini ${ }^{45}$ que relata que nesta época os portugueses não tinham apoio à emigração, uma vez que o governo salazarista via a saída dos seus como uma perda de mão de obra para a lavoura e para a indústria. Mas, ao mesmo tempo, não se proibia

\footnotetext{
$45 \quad$ Fiamoncini 2008: 18.
} 
tal prática, já que muitos dos portugueses que moravam no Brasil mandavam valioso capital para suas famílias, o que ajudava a frágil economia portuguesa.

Através dos relatos obtidos e das fontes bibliográficas acessadas, evidencia-se que as condições econômicas de cada um desses portugueses, muitas vezes determinadas pelo local de nascimento, podiam condicionar a uma alimentação menos diversificada, como no caso principalmente dos que moravam no interior. Há exemplos referentes ao escasso consumo de carne, item normalmente caro para se ter, além de estar atrelado à necessidade de conservação. O Sr.J.G. comenta que:

"lá não se comia carne de boi como aqui. Eu fui comer a primeira vez aos 18 anos. [...] Comia outras carnes porque o boi era para trabalhar".

“[...] na minha terra eu comia um pedaço de galinha quando era Natal. [...] naquele tempo lá era duro, era sofrido. A gente comia umas batatas, mas carne que era bom.... ninguém via. Meus pais tinham uma lavoura, trabalhávamos o trigo, centeio e batatas... e se vivia com aquilo. Matávamos, às vezes, um porquinho no inverno, no Natal e aí conservava aquelas carnes. Hoje é diferente... a vida lá é boa. Mas, naquele tempo...”(J.M.P.)

Enquanto que aqueles que nasciam próximos ou nas grandes cidades, tinham maior probabilidade de ter os pais exercendo trabalhos que não o da lavoura, com funções assalariadas, tornando mais possível o acesso a uma maior diversidade de alimentos. O Sr. M.A.S.C., 70 anos, proveniente da Região de Condeixa-a-nova, situada muito próxima à Coimbra, faz esta distinção entre o interior e a cidade grande, em seu relato:

"Eu, quando saí aos três anos de Coimbra, fui para Caldas da Rainha, que fica a $80 \mathrm{~km}$ de Lisboa, lá a vida era um pouquinho mais fácil... não era tão difícil como no interior, e quanto a comida talvez eu tinha um pouco mais de vantagem, porque meu primeiro emprego, foi como magarefe [açougueiro] [...] ajudava a preparar a linguiça, toucinho, então tinha um pouco mais de vantagem".

“[...] meu pai era funcionário do governo, por isso viajávamos muito. [...] minha mãe diz que desde pequenininha que eu não comia ervilhas, eu jogava fora [...] minha mãe fazia frango de fricassê, frango com ervilhas, língua com ervilhas, essas coisas". (F.M., 54 anos, Vila do Conde, litoral, pertencente ao Distrito do Porto)

“[...] minha mãe, ao domingo, se estivéssemos em Nelas [Algirás, Beira Alta] fazia muito o cabrito, aquele arroz de frango ao molho pardo, peixe, carne, bacalhau, lulas... a alimentação era bastante 
Memórias da alimentação e fatos da imigração de luso-brasileiros moradores de uma cidade do sul do Brasil

variada. Durante a semana buscava se fazer de tudo". (V.R.F.P., 77 anos, Nelas, Beira Alta).

Destarte, fica evidente o leito lúgubre no qual Portugal deitava-se, fazendo com que seus filhos fossem buscar alternativas para esta mudança de cenário, por vezes, encontrada na emigração. Nadalin ${ }^{46}$ afirma que "migrações são fenômenos sociais, eminentemente históricos e que o ato de migrar está associado ao cotidiano, à procura de algo melhor, sempre mais adiante". Esta afirmação de Nadalin mostra-se como um resumo do contexto em que se deram as emigrações destes entrevistados, além de permitir vislumbrar que a busca de uma vida melhor, mais cheia de fartura, foi o que propulsionou estes portugueses às mudanças drásticas de vida e de país.

\section{IMIGRANTES: ESPERANÇAS E ILUSÕES BEM ALIMENTADAS NO ALÉM-MAR?}

Alimentados por esperanças e ilusões de melhoria de vida, o português partiu em busca de um novo espaço, e algumas vezes, veio encontrar aqui, do outro lado do Atlântico, sem, no entanto, obliterar as boas lembranças da sua verdadeira terra.

A decisão pela emigração, impulsionada pelo momento soturno e de tensão vivenciado pela Europa ditadora, fez com que muitos destes portugueses singrassem para o Brasil, assim como já retratado. Em geral, a vinda era intermediada por parentes ou amigos que já haviam aqui se estabelecido, e lhes enviavam as cartas de chamada ${ }^{47}$, alvissareiras, vistas por muitos como a possibilidade de melhorar de vida, ou de "fazer a vida", como muitos depoentes colocam.

Entretanto, nem sempre a carta de chamada era a garantia de vinda. Alguns recebiam junto da carta, o subsídio necessário para arcar com as despesas da viagem. Outros tinham ao menos a promessa de trabalho, como no caso do $\mathrm{Sr}$. A.J.F. Outros ainda, tinham que contar com muito esforço e sorte, levando-os a vender o que pudessem para apostar na vicissitude, que correspondesse à expectativa alimentada pela crença de que o Brasil era um país melhor.

“[...] naquele tempo quem tinha um terreninho lá na aldeia vendia para arrumar um dinheirinho, porque dinheiro ninguém tinha para

\footnotetext{
46 Apud Passos 2009: 11.
}

47 Estas cartas eram documentos que declaravam uma garantia de auxílio ao imigrante que pretendesse se juntar à sua família já instalada no Brasil. Nesse sentido, as cartas de chamada faziam parte da burocracia para tirar o passaporte em Portugal e, a partir de 1920, passaram a ser obrigatórias para que os imigrantes entrassem pelos portos brasileiros. 
vir, mas quem conseguisse ter, só queria vir para cá. Naquele tempo, o Brasil era bom”. (J.M.P.)

“[...] para que eu conseguisse vir para cá, meus pais tiveram que vender a única vaca que tínhamos. Era nosso único bem e, assim que cheguei, trabalhei para pelo menos mandar dinheiro para eles, por conta disso". (M.A.T.S.)

"[...] a gente tinha muito pouco dinheiro lá e meus pais venderam a venda que tínhamos para poder comprar as passagens dele [o pai] e a do meu irmão. Depois, ficamos esperando eles mandarem dinheiro para comprar as nossas passagens, para que o resto da família viesse para cá. [...] isso demorou 7 anos, praticamente”. (A.S.S., 75 anos, Lomba, Sabugal)

“[...] as pessoas recebiam as cartas desses amigos ou de parentes, avisando e convidando pra vir pra cá $[. .$.$] mas, era preciso uma tal carta$ de chamada [...] Pensei que seria mais fácil porque eu falava a língua e porque já tinham me falado que a comida era muito parecida e abundante". (M.A.T.S.)

Nem sempre o desembarque era direto no estado do Paraná. Aliás, era muito comum que este grupo em especial fizesse uma passagem primeiramente por São Paulo ou Rio de Janeiro. A partir das atividades que começavam a desenvolver no comércio, muitos acabavam por conhecer o estado do Paraná ou outras localidades do interior dos locais onde viviam, seja por suas atividades de mascate ou por perceberem oportunidades de trabalho nestas outras regiões, conforme citado por diversos autores já referenciados neste estudo, e conforme cita o Sr. J.M.P., em sua entrevista:

“[...] eu fiquei ainda dois, três anos em São Paulo. Depois comecei a viajar para cá, porque naquele tempo a gente vendia coisas na rua [...]”.

"[...] comecei minha vida como feirante. Vim de Portugal para trabalhar com um primo, na feira. Como a gente ganhava muito pouco, comecei a vender coisas de porta em porta para complementar minha renda e acabei por virar mascate no interior de São Paulo". (M.A.T.S.)

"Eu era carregador de supermercado em São Paulo. Fiquei muitos anos fazendo isso por lá. Depois fui para o interior de São Paulo, atraído por um novo emprego e de lá vim para Curitiba porque um amigo meu, que era da minha terra, me convidou para trabalhar aqui em Curitiba, no Dias Martins”. (A.M.L.)

Suas reimigrações para o Paraná acabavam por estar associadas ao clima, muitas vezes referido como sendo muito semelhante ao de Portugal. Também figuram aqui as oportunidades de expansão do negócio, com pouca concorrência e grande oferta de fregueses que necessitavam de mercadorias, 
Memórias da alimentação e fatos da imigração de luso-brasileiros moradores de uma cidade do sul do Brasil

visto o contexto da urbanização de Curitiba e, estando já familiarizados com o comércio em outros locais do Brasil, encontravam aqui o mercado em expansão que lhes parecia mais favorável. Ou vinham ainda, por uma simples garantia de trabalho.

“[...] meu pai chegou em Santos. Foi para São Paulo e depois veio parar em Curitiba. Lá ele foi feirante e depois foi chamado por um conterrâneo que conheceu em São Paulo para vir trabalhar aqui. Veio para cá trabalhar como carregador em uns mercados e armazéns e depois virou ambulante, vendendo pipoca na Praça Santos Andrade”. (A.S.S.)

“[...] os tios que já estavam aqui, tinham uma distribuidora de doces em São Paulo, e aí pegaram meu pai e meu tio e falavam: 'vão passear, vão trabalhar' e aí meu pai principalmente começou a percorrer o Paraná. [...] Acabou gostando em função do clima”. (M.F.G.)

Consumada a vinda, o português se estabeleceu principalmente no comércio, conforme já abordado, aproveitando-se da demanda que este mercado apontava, e também porque era o meio em que normalmente já haviam se inserido aqueles que os traziam através das referidas cartas de chamada.

Depois de estabelecido em Curitiba, o Sr. J.M.P, ainda trabalhou com representações de algumas empresas, e teve lanchonete e panificadora, inclusive fora da cidade, no litoral do estado:

“[...] depois de estar aqui e ter algum dinheiro, tive uma representação dos Doces Campineira e novamente a gente viajava, mas por aqui pelo estado mesmo. Depois comprei a representação da Tostines [...]. Em 1962 comprei um caminhãozinho e viajei durante dezesseis anos para Cascavel e Campo Mourão. Depois tive uma lanchonete próximo ao Detran aqui, que até então só existia um. Tive panificadora em Paranaguá”. (J.M.P.)

Todos os entrevistados do gênero masculino relataram ter começado suas vidas no comércio do Paraná. Mercearias, panificadoras, restaurantes, ou mesmo pequenas representações, foram os serviços prestados, seja como proprietários ou como funcionários. Alguns inclusive, mantém seus comércios até os dias atuais. Entretanto, nem todas as coisas aconteceram da forma sonhada. O sucesso, a abundância e as facilidades tão sonhadas e imaginadas nem sempre foram alcançadas pelos portugueses imigrados. Boschilia ${ }^{48}$ expressa a necessidade de problematizar as escolhas e estratégias adotadas pelos imigrantes na sociedade de destino, uma vez que sua experiência não se encerra com o fenômeno do deslocamento transnacional, tampouco com sua decisão de permanecer na

48 Boschilia 2012: 95. 
sociedade de acolhimento. Uma reflexão sobre o alcance das expectativas destes senhores e senhoras, depois de firmados neste continente, permite aferir que nem sempre encontraram o Brasil do seu imaginário.

Nos escritos de $\mathrm{S}_{\operatorname{cott}}{ }^{49}$, expõe-se que o fluxo emigratório português dos anos 60, diferiam dos tradicionais direcionados ao Brasil. A industrialização gerada no pós-guerra em determinados países, constituía fator atrativo, mas a intenção da maioria dos portugueses era a de angariar recursos para uma vida melhor em um retorno à Portugal:

a maioria dos portugueses que partiam esperavam que a ausência da terra natal fosse temporária. A intenção dos emigrantes era de trabalhar alguns anos nos países escolhidos como destino, de modo a bancar uma vida melhor na volta a Portugal. De alguma maneira esse projeto também se adequava aos interesses dos países receptores, pois veriam suprida a necessidade de mão de obra barata sem serem obrigados a acolher toda aquela gente no longo prazo.

Um fato destacado pela autora é a constatação de duas situações inerentes aos portugueses que regressaram: os que ficaram satisfeitos com o que conseguiram amealhar, e os que viram seus planos fracassar perante as dificuldades encontradas no estrangeiro. E, quanto aos que não cumpriram com o ideal de regresso, estes, foram a maioria, que acabaram se transformando em "núcleos familiares multigeracionais de luso-descendentes", tendo procurado se inserir na comunidade de destino, apesar do desejo de se manter ligação com o que ficou para trás - terra natal, amigos, hábitos, tradições $^{50}$.

Ao chegarem aqui tiveram dificuldades em se estabelecer, sofrendo agruras para adaptação e para ganhar a vida. As condições financeiras de trabalho não facilitaram a vida e a retenção de dinheiro para estes lusitanos recém-chegados. Comprar o que dava com o pouco dinheiro que ganhavam, constatando que nem sempre a facilidade prometida se cumpria, fazia com que muitos imigrantes cumprissem longas e duras jornadas de trabalho, chegando a se estender por 16 horas no comércio e varejo.

“[...] quando cheguei eu precisava arranjar emprego, para poder comer e ter onde morar. Eu só pensava em poder comer... nem que fosse só as batatas e as cebolas que comi por semanas". (M.A.T.S)

Por vergonha de uma evidenciação do fracasso financeiro ou pela falta de recursos para o retorno, muitos aqui permaneceram. Voltar nas mesmas condições, ou em condições piores às de suas vindas, era percebido por muitos

\footnotetext{
49 Scott 2010: 151.

50 Scott 2010: 151.
} 
Memórias da alimentação e fatos da imigração de luso-brasileiros moradores de uma cidade do sul do Brasil

como uma vergonha pessoal, um fracasso evidente. Muitos, por estas razões foram forçados a permanecer na terra que os recebeu. Não acharam no Brasil um terreno de riquezas, e sim de muito trabalho.

“[...] Nunca voltei de vergonha porque eu não queria voltar com uma mão na frente e outra atrás, sem dinheiro e sem ter como pagar a passagem de volta [...] se eu não tinha nem dinheiro para comer direito aqui, como eu ia voltar?”. (M.A.T.S.)

“[...] O fato é que lá, até para comprar sal e peixe era muito difícil. Aqui, para conseguir comer e sobreviver, também foi [...] tudo bem que aqui a variedade de alimentos era muito maior, mas... como eu não conseguia comprar, nem sei se era uma vantagem”. (M.A.T.S.)

E, trabalhavam de sol-a-sol para conseguir manter-se e criar raízes, muito mais profundas (em relação ao tempo de suas vidas nesse novo mundo) do que as que deixaram para trás. Vieram crianças ou jovens adultos e aqui cresceram e envelheceram, muitos sem ter tido, até hoje, condições de voltar à terrinha natal, mesmo que para uma simples visita. Por este motivo, procuravam usufruir o melhor possível dos dois mundos.

\section{Sabores e saberes lusitanos X Condições de acomodação}

Considerando oportunamente os contextos anunciados a respeito das rupturas às quais os hábitos e a alimentação estão sujeitos, o momento de imigração é entendido aqui, como o primeiro baque com o qual sofrerá o português, observando que este veio com atos consolidados em seu modo de viver. Os saberes e sabores oriundos dos costumes, tornam-se vulneráveis à maré em que se lança o emigrante, acarretando em interferências, ora boas, ora nem tanto, nos seus hábitos em diversos setores da sua vida, mas principalmente e ao que irá interessar, na sua alimentação.

A fome ou a monotonia alimentar muitas vezes serviu como grande propulsora da vontade de se lançar ao mar em busca de melhoria e abundância. Ao alcançar o primeiro objetivo, que era o de emigrar, o português se estabeleceu, e seguiu, literalmente, trabalhando na busca pelo seu "pão de cada dia”, e ainda teve que lidar, como o constatado através dos depoimentos, não somente com a questão da disponibilidade dos alimentos, mas principalmente com a acessibilidade, haja visto que o fato do alimento estar disponível não queria dizer necessariamente que estava acessível às mãos do português, principalmente por questões econômicas.

Nos relatos sobre suas vidas em terras brasileiras, particularidades e peculiaridades no percurso de cada um vem à tona, e é quando começam a 
se estabelecer as diferenças dentre os entrevistados. Apesar de vários "lugares comuns”, cada um irá se inserir de maneira bastante diferente, gerando a estes estudos, amplos caminhos a serem percorridos. Há os que emigraram sozinhos, homens, que pela necessidade emergente de trabalho, optaram por uma espécie de alimentação que melhor se adequava a sua falta de tempo para cozinhar. O Sr. A.M.L. conta que veio sozinho para cá, e que: “[...] ficava difícil comprar a comida e fazer. Era bem mais fácil comer fora de casa e onde eu achava comida, acabava comendo". Buscaram os restaurantes, pela facilidade ofertada no tocante à refeição e, consequentemente, passaram a conhecer as iguarias nunca antes provadas, ou as diferentes formas de disponibilidade do alimento que já lhes era familiar. Há também os que se estabeleceram em pensões, e que conseguiram fazer suas refeições a partir destes locais. Outros que se limitavam a escolha de uma refeição, como um café da manhã reforçado, ou apenas o almoço, acreditando que esse esforço geraria a mudança almejada para o futuro.

Durante as entrevistas, foram comuns alguns comentários sobre comidas que estes portugueses foram encontrar ou experimentar somente aqui, em terras paranaenses. Um dos entrevistados cita a lembrança da primeira vez que provou o pinhão ${ }^{51}$. A Sra. M.F.G., portuguesa de segunda geração, conta como sua mãe se encantou pela maionese ${ }^{52}$, fazendo deste prato um preparo constantemente presente na sua alimentação, chegando inclusive a leva-lo à Portugal para apresentar as irmãs.

“[...] eu preferi morar em uma pensão porque lá eu pagava tudo junto, para morar e comer. [...] lá eu tinha tudo pronto e mais fácil para mim. Foi lá que aprendi a comer e conheci um monte de coisas que nunca tinha visto e comido em Portugal”. (M.A.T.S.)

“[...] lá [no restaurante perto da fábrica de fitas] eles serviam os pratos de comida e cada dia tinha uma coisa diferente. Muitos legumes, batata, carnes e peixes, a gente já tava acostumado a comer, mas lembro de um monte de coisas que eu nunca tinha visto antes... [...] tipo dobradinha, feijoada, essas coisas". (Sra. D.S.L., 70 anos, Lomba, Sabugal)

A busca pelo comer fora foi algo que se fortaleceu na vida desses imigrantes, principalmente os do gênero masculino, encarada como a alternativa à falta de suas mães ou esposas, provedoras do comer. Vale lembrar que aspectos como o crescimento da cidade de Curitiba, podem ter surtido como um dos fatores corroborantes para esta prática, já que passaram a ter cada vez mais opções ofertadas no mercado de consumo. No entanto, como sua base de

\footnotetext{
51 Semente comestível do pinheiro, árvore comum no Estado do Paraná.

52 Salada de batatas com molho de maionese.
} 
Memórias da alimentação e fatos da imigração de luso-brasileiros moradores de uma cidade do sul do Brasil

alimentação era bastante simples, poucos tinham condições de diversificar, acarretando em rotinas alimentares.

“[...] como eu comia todos os dias em restaurantes [...], chegou uma hora que eu não aguentava mais comer tanto arroz. Era arroz todo dia [...] e cheguei a enjoar!". (A.M.L.)

"[...] meu pai trabalhava no Centro e ele comia fora na hora do almoço. $\mathrm{Na}$ verdade ele sempre comia um lanche e tomava gasosa. Ele amava gasosa $^{53 "}$. (A.S.S.)

“[...] Eu amava comer o bife à milanesa e sempre comia nos restaurantes perto da fábrica que eu trabalhava. Lá em Portugal eu nunca tinha comido bife à milanesa. [...] nem sei se tinha isso lá”. (D.S.L.)

Por outro lado, há a percepção de que aqueles que vinham acompanhados de suas esposas, já com família, ou com suas mães, tendem a ter uma melhor manutenção dos hábitos, uma vez que a vinda da mulher permitirá o acesso ao alimento preparado em casa, onde ela será a responsável pela manutenção, através da tentativa de se reproduzir o que comiam em Portugal, como explícito no comentário do Sr. A.J.F.: "[...] a comida, logo que viemos, era minha mulher quem fazia. Minha mulher veio comigo. Aí eu quase não sentia falta [da alimentação de Portugal]”.

“[...] Eu vim pra cá com minha mãe e irmãos. Meu pai já tinha uma casa onde fomos morar. Lá a mãe fazia as coisas que a gente tava acostumado a comer, mas de vez em quando aparecia uma coisa diferente [...]". (J.J.S., 62 anos, Lomba, Sabugal)

“[...] minha mãe veio casada com uns 23 ou 24 anos, junto do meu pai, há 52 anos atrás, e mais minha irmã, que tinha 4 anos na época. Minha mãe e meu pai sempre tiveram uma sopinha a noite, que era indispensável. O pão português [do hábito do português], azeite de oliva próprio português. Dificilmente colocamos manteiga na comida. Usamos o Azeite. [...] Lá [em Portugal] eles comem muita sopa. Minha mãe sempre fez muita sopa aqui. Sopa de couve, de feijão com couves. Ela come até hoje, sopa todos os dias!”. (M.F.G.).

"[...] o meu casamento é um dos motivos para eu ter mantido os hábitos de comer, já que vim para o Brasil casada com um português, e aqui ficamos juntos e formamos família. [...] Ele sempre gostou de comer a comida de lá e eu sempre fiz em nossa casa”. (F.M.)

53 Gasosa Cini, marca de refrigerante (soda) típica do Paraná. 
Os entrevistados Sr. M.A.T.S. e Sr. A.M.L, são exemplos expressivos destas perspectivas de vinda solitária, do comer fora e do casamento, como influenciadores dos hábitos. Eles vieram solteiros para o Brasil e foram inseridos no contexto de pensões e de restaurantes, com profundo impacto em uma monotonia alimentar. Após casamento, já no território brasileiro, voltaram a consumir os alimentos da terrinha, já que escolheram conterrâneas para seus enlaces. O casamento entre portugueses foi percebido em uma boa parte dos entrevistados. Pessoas que vieram de regiões diferentes, em períodos diferentes e que se encontraram em terra brasileira e que, comungando de sentimentos semelhantes, se uniram e formaram famílias, ajudando com que costumes e hábitos alimentares se perpetuassem ao longo dos anos.

"[...] depois que me casei, e comecei a comer em casa, muitas coisas que eu comia em Portugal passei a comer dentro da minha casa mesmo. [...] Mesmo com adaptações de alguns alimentos, conseguimos manter as comidinhas de lá. Comemos sopa todos os dias e o pão nunca sai da mesa”. (M.A.T.S.)

Muitos, tendo vindo sós ou com suas famílias, mantendo ou não seus hábitos nesta nova terra, referenciam ainda que a falta do alimento ou ingrediente em alguns momentos de suas refeições, não tem correlação com a facilidade de acesso, e sim com a cultura alimentar local, imposta em alguns momentos de suas rotinas. À exemplo, a fala do Sr. J.M.P., dizendo que: "[...] aqui ninguém come pão com a comida. Não sei comer sem pão"; e a do Sr. M.A.S.C.: “[...] numa casa portuguesa, na hora do almoço ou da janta, tem pão na mesa”.

"[...] quando comia fora nunca conseguia comer meu pãozinho do dia-a-dia, porque aqui ninguém come pão com a comida. Nos restaurantes nunca via isso e sentia falta”. (A.S.S.)

“[...] eu senti diferença na alimentação, porque não tinha pão. Tinha carne, e para eu me habituar a comer carne sem pão foi triste. Cá, ao sair para vender, parava nos restaurantes e ninguém punha o pão na mesa. Tinha que comer sem pão. Ainda hoje como com pão. Vou almoçar e como com pão. Dia desses ainda fui almoçar fora, peguei na minha panificadora um pão, enfiei aqui no bolso e levei para o restaurante". (A.J.F.)

Atualmente, na opinião deles, a variedade de alimentos importados de Portugal ofertados em Curitiba, faz com que quase não tenham dificuldades para encontrar alguns ingredientes. No entanto, para os entrevistados, esta disponibilidade nem sempre é condizente com a qualidade que tinham dos mesmos alimentos enquanto moravam lá, principalmente no que se refere ao sabor. Por mais que o alimento seja oriundo de Portugal, os processos 
Memórias da alimentação e fatos da imigração de luso-brasileiros moradores de uma cidade do sul do Brasil

necessários à importação a fim de manter a integridade do alimento, acabam afetando no sabor, trazendo algo diferente do que lhes guarda a memória.

“[...] aqui tem mais variedade, mas não tem o mesmo sabor que a de lá”. (J.M.P.)

"[...] sinto falta de algumas coisas que a gente se habituou e que aqui não tem. Ou aqui tem, mas não é igual. Por exemplo a sardinha. A sardinha portuguesa não se compara com a sardinha daqui”. (M.A.S.C.)

“[...] sabe que tem a sardinha portuguesa a vender, mas elas já estão tão congeladas que perderam o gosto”. (A.J.F.)

“[...] essas coisas me fazem falta porque as daqui não são iguais. [...] muitas vezes prefiro até deixar de comer, já que o gosto não é o mesmo". (M.A.T.S.)

“[...] tem coisas que guardo o gosto na memória e me enche a boca de água só de lembrar. [...] tem coisas que a gente consegue fazer igual aqui, e tem coisas que não tem igual as de lá”. (A.S.S.)

Por fim, de maneira geral, se percebe que por razões diversas, mesmo que todos os hábitos não tenham sido mantidos, quando se vai para a cozinha e se produzem as refeições, são as tradições e os alimentos da infância que falam mais alto e que vêm à tona, fazendo-se notar misturas e integrações de alimentos e costumes.

A memória gustativa e sentimental que se atrela ao consumo é nítida nestes imigrantes. Rituais são mantidos ou buscados constantemente como forma de aproximação e manutenção do pertencimento ao território português.

Seja no pão que leva no bolso, no azeite que derrama no prato, ou na bagagem que traz, o português acaba por demonstrar que não há "sardinha que não seja puxada para sua brasa”, fazendo sempre reavivar seu sentimento de pertença.

Lembranças, memórias e sentimentos: ingredientes desta poção mágica da imigração.

\section{Considerações Finais}

A busca pelo alimento motiva o homem desde seu surgimento. Reflexões que levam o ato de alimentar-se para além do termo "nutrir-se" são exploradas desde a Bíblia. Comer como ato de alimentar a alma, e não somente o corpo. Comer como ato de sociabilidade. Comer para sobreviver.

Neste sentido, as mudanças de local ou as "migrações" em função do alimento deixam marcas na história, a fim de que se possa um dia retratá-las, 
e então chegar à observância de que o alimento, ou a busca por ele, é capaz de determinar rumos a se percorrer.

O emigrante português mostra-se em interação com o nosso povo desde que nos descobriram. Sendo assim, o que é o nosso povo senão descendente destes portugueses? Não necessariamente descendentes de sangue, mas marcadamente de costumes que permeiam o tempo e continuam a ditar e sofrer interferências. Fato é que a interferência não obrigatoriamente altera a essência. Estando em terras brasileiras, o português deu vez à criatividade e temperou como sabia, àquilo que dispunha.

Objetivando, neste trabalho, identificar as memórias alimentares e os fatores da imigração de luso-brasileiros que residem atualmente em Curitiba, bem como as influências geradoras dos seus hábitos, foi utilizada a ferramenta que se julgou mais adequada para o relato desta história contemporânea: a história oral, através de entrevistas com portugueses prioritariamente de primeira geração, e posteriormente, com o cruzamento de dados bibliográficos sobre o passado. Uma vez alicerçados, encontraram-se os pontos coincidentes que levaram a dar créditos e respaldam estas considerações, possibilitando reconstruir e melhor entender os caminhos e os motivos que desencadearam a emigração deste povo, e determinaram sua alimentação.

Várias são as razões que levam os homens a emigrar. No caso destes portugueses, o contexto angustiante pelo qual Portugal passou na primeira metade do século $\mathrm{XX}$, desencadeado por um período de ditadura e munido de tensão em função de conflitos de ordem mundial que se estabeleceram, cadenciaram momentos e sentimentos controversos, de medo, angústia e escassez, fazendo com que a mudança fosse vislumbrada no além-mar.

O Brasil, ex-colônia portuguesa, ainda visto no imaginário destes portugueses como terra de abundância, constituiu um dos seus destinos, observado também o momento de crescimento urbano pelo qual algumas cidades brasileiras passavam.

Tal crescimento foi constatado de forma ampla e instantânea em Curitiba, que passou a atrair vários contingentes, dentre eles, alguns portugueses que já moravam em grandes cidades brasileiras, a exemplo de São Paulo e Rio de Janeiro, e acabaram por se estabelecer, de modo geral, no comércio, aproveitando-se de uma demanda que o mercado apontava necessária.

No decorrer da vida destes entrevistados, muitos são os fatores observados que afetam sua alimentação, ou até mesmo, limitam-na.

Ao lembrarem da alimentação que os acompanhou em suas infâncias e adolescências, percebe-se que o ofício dos pais era um dos determinantes sociais da diversidade alimentar das famílias. Além disso, a escassez de alimentos, aliada por vezes à indigência e aos sentimentos melindrosos, marcam esta época, propulsando a emigração, a busca pela fartura e por uma vida mais digna. 
A fixação deste povo em terras brasileiras é vista como o primeiro grande baque sofrido pela alimentação, desencadeado não somente pela inserção em uma cultura diferente da sua, mas principalmente pelas condições em que se colocará o português, a fim de alcançar as mudanças almejadas.

Dentre o grupo de estudo, classificou-se pela peculiaridade que se estabeleceu, alguns entrevistados, homens, que aqui desembarcaram sozinhos. A análise permite observar que para estes, o tempo tomado pela necessidade de trabalho, mostrava-se um empecilho para o ato de cozinhar, fazendo com que suas refeições fossem em restaurantes, ou nas fábricas onde trabalhavam, ficando a mercê do que lhes era servido, e que quase sempre, não estavam habituados. Sendo assim, o indivíduo que vive sozinho, seja por razões como separação, viuvez, ou simples escolha, normalmente passa menos tempo na cozinha, intensificando o comer fora. Por ser a manutenção do hábito, carente de partilha e execução, o viver sozinho mostra-se como uma barreira à propagação do costume, pois, para que se "perpetue" é necessário que se pratique e se tenha alguém para quem transmitir.

Em contrapartida, para os que vinham acompanhados de suas esposas, ou aqui estabeleciam vida conjugal, a principal influência observada é marcada pelo gênero, no caso, feminino. A mulher foi percebida como a principal mantenedora dos hábitos alimentares. A este fato atrela-se a ligação que se atribui à mulher com a cozinha, sendo este espaço visto como um espaço feminino. Por ser a mulher responsável pela escolha do que porá à mesa, assim como pelo preparo dos alimentos, fica expresso que a dominação dos saberes culinários e a transmissão destes saberes, passam por suas mãos, levando-a ao status de detentora do hábito alimentar, seja essa representada na figura de mãe, esposa, filha ou empregada. Salienta-se, que essa temática, aqui pouco aprofundada, expõe-se como sugestão para trabalhos posteriores, que enfoquem este contexto.

Em suma, a vida adulta mostra-se, portanto, como a passagem mais propensa à alterações nos hábitos, que podem derivar de fatores de cunho social, biológico, econômico ou mesmo de gênero, uma vez que separações, vida conjugal, ou doenças que afetam a alimentação são elementos aos quais todos os indivíduos estão submetidos, confirmando o conceito de que as cozinhas estão em constante transformação e sujeitas à rupturas a qualquer momento, incorporando novos hábitos, mesmo que sorrateiramente, passando a constituir um novo costume.

No entanto, não se deixa de ressaltar, nas palavras de Reinhardt ${ }^{54}$, o "poder que a comida tem de desencadear lembranças, reestruturando nossa memória”, resumindo que o português, assim o faz. Por mais que os hábitos não sejam mantidos integralmente, todos, ao adentrarem em uma cozinha,

\footnotetext{
$54 \quad$ Reinhardt 2012: 161.
} 
buscam temperar seus preparos com saudades e lembranças do gosto, fazendo reavivar através do paladar, o elo do imigrante com as suas raízes.

\section{REFERENCIAS}

Boschilia, R. (2012), "À procura de um novo destino: imigrantes portugueses no Paraná da segunda metade do século XIX", História: Questôes E̋ Debates 56.1: 87-112. Disponível em: <https://revistas.ufpr.br/historia/article/view/28641/18827>, Acesso em: 04 maio 2015.

Braga, I. D. (2015), "A culinária portuguesa no tempo da II Guerra Mundial: as receitas, o racionamento e as soluções alternativas", Helikon 2.3: 3-25, Disponível em: $<$ www2.pucpr.br/reol/pb/index.php/helikon?dd1=15296\&dd99=view\&dd98= $\mathrm{pb}>$, Acesso em: 14 jul. 2015.

Brasil. Embaixada de Portugal no Brasil (2011), Comunidade Portuguesa, Disponível em: <www.embaixadadeportugal.org.br/comunidade.php>, Acesso em: 17 maio 2015.

Cascudo, L. C. (2004, 3. a ed.), História da Alimentação no Brasil, Global, São Paulo.

Consiglieri, C.; Abel, M. (2001, 2. ${ }^{\text {a }}$ ed.), "A contribuição portuguesa", in C. Fernandes, Viagem gastronômica através do Brasil, Senac-SP, Estúdio Sonia Robatto, São Paulo, 16-19.

Fernandes, C. (2001, 2. ${ }^{a}$ ed.), Viagem gastronômica através do Brasil, Senac-SP, Estúdio Sonia Robatto, São Paulo.

Fiamoncini, C. (2011), Em defesa da saúde e do amparo: imigrantes portugueses em Curitiba (1898-1930), 146 f., Dissertação de Mestrado, Programa de Pós-Graduação em História, Universidade Federal do Paraná, Curitiba.

Fiamoncini, C. (2008), Imigração, cultura e identidade: portugueses e o comércio em Curitiba no final do século XIX, 82 f., Monografia de Graduação, Licenciatura e Bacharelado em História, Universidade Federal do Paraná, Curitiba.

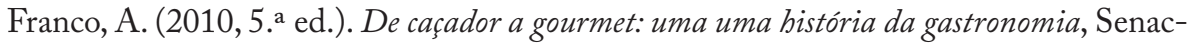
SP, São Paulo.

Morais, C. et al. (2012). "From childhood to old age: a qualitative approach to the study of Portuguese ederly's perception of meals across the life cycle", Revista SPCNA 18.1: 8-18, Disponível em: <http://www.spcna.pt/download.php?path=pdfs\&filename =REV_2012_1_019-027_Rah_2012_1_artigo_3.pdf>, Acesso em: 27 ago. 2014.

MORE (2013),Mecanismo online para referências, versão 2.0,UFSC, Rexlab, Florianópolis, Disponível em: <http://www.more.ufsc.br/>, Acesso em: 04 jun. 2015.

Nogueira,F. (2001,5. a ed.), Salazar: as grandes crises (1936-1945), Civilização Editora,Lisboa.

Pasckes, M. L. N. A. (1991), "Notas sobre os imigrantes portugueses no Brasil: (sécs. XIX e XX)", Revista de História 123-124: 81-93, Disponível em: <http://dx.doi. org/10.11606/issn.2316-9141.v0i123-124p81-93>, Acesso em: 03 jun. 2015.

Passos, G. C. (2009), A presença dos imigrantes portugueses no Paraná na segunda metade do século XIX, 64 f., Monografia de Graduação, Bacharelado em História, Universidade Federal do Paraná, Curitiba. 
Memórias da alimentação e fatos da imigração de luso-brasileiros moradores de uma cidade do sul do Brasil

Paulo, H. H. J. (1997), Aqui também é Portugal: a colónia portuguesa do Brasil e o salazarismo, Tese de Doutorado, Departamento de História, Arqueologia e Artes, Universidade de Coimbra, Coimbra, Disponível em: <https://estudogeral.sib. uc.pt/handle/10316/692>, Acesso em: 21 maio 2015.

Reichembach, M. T. (2007), História e alimentação: o advento do fast food e as mudanças dos hábitos alimentares em Curitiba (1960-2002), 169 f., Tese de Doutorado, PósGraduação em História, Universidade Federal do Paraná, Curitiba.

Reinhardt, J. C. (2012), Dize-me o que comes e te direi quem és: alemães, comida e identidade, Máquina de Escrever, Curitiba.

Ribeiro, C. G. S. (2013), Tudo pronto! O comer fora e o prazer reinventado: história dos restaurantes "por quilo" de Curitiba, Máquina de Escrever, Curitiba.

Ribeiro, C. G. S. (2015), "Portugueses no além-mar e a imigração ao longo das décadas de 1950 e 1960: motivações e saudades de um grupo familiar”, in C. Soares, C. G. S. Ribeiro (coords.), Odisseia de Sabores da Lusofonia, Imprensa da Universidade de Coimbra/PUCPRESS, Coimbra-Curitiba, 229-251.

Rocha, R., Pires, H. S. (2001, 11. ${ }^{a}$ ed.), Minidicionário Ruth Rocha, Scipione, São Paulo.

Santos, C. R. A. (1995), História da Alimentação no Paraná, Fundação Cultural, Curitiba.

Santos, C. R. A. (2007, 2. a ed.), História da Alimentação no Paraná, Juruá, Curitiba.

Scott, A. S. (2010), Os Portugueses, Contexto, São Paulo.

\section{Fontes ORAIS}

Sociedade Beneficente Portuguesa Primeiro de Dezembro. Secretaria da Sociedade Portuguesa Primeiro de Dezembro.

Sr. A.J.F., 85 anos, Castelo Branco, Entrevista concedida em: 18 abr. 2015.

Sr. A.L.S., 68 anos, Lomba - Sabugal, Entrevista concedida em: 13 dez. 2014.

Sr. A.M.L., 78 anos, Proença-a-Nova - Castelo Branco, Entrevista concedida em: 05 dez. 2014.

Sr. A.S.S., 75 anos, Lomba - Sabugal, Entrevista concedida em: 12 dez. 2014.

Sra. D.S.L., 70 anos, Lomba - Sabugal, Entrevista concedida em: 01 dez. 2014.

Sra.F.M., 54 anos, Vila do Conde - Distrito do Porto, Entrevista concedida em: 13 mar. 2015.

Sr.J.G., 73 anos, Proença-a-Nova - Castelo Branco, Entrevista concedida em: 03 maio 2015.

Sr. J.J.S., 62 anos, Lomba - Sabugal, Entrevista concedida em: 01 dez. 2014.

Sr. J.M.P., 86 anos, Miranda do Douro, Entrevista concedida em: 18 abr. 2015.

Sr. M.A.S.C., 70 anos, Condeixa-a-nova, Entrevista concedida em: 18 abr. 2015.

Sr.M.A.T.S., 74 anos, Gião - Candemil - Amarante, Entrevista concedida em: 01 dez. 2014.

Sra. M.F.G., 51 anos, filha de portugueses provenientes de Beira Alta, Entrevista concedida em: 19 dez. 2014.

Sr. V.R.F.P., 77 anos, Nelas - Beira Alta, Entrevista concedida em: 20 mar. 2015. 
Cilene da Silva Gomes Ribeiro, Marcus Vinícius Soares, Mariana de Moraes e Silva de Araújo

\section{Audiovisual}

OS ANOS da Ditadura Salazarista 1993 (EBM). Direção de António Rocha, Clarisse Mendes, Laura C. Moreira, Manuel Pires, Manuela Brazão, Maria José Garção, Natália Belchior, Odete Martin. Produção de António Rocha, Laura C. Moreira, Manuel Pires. Realização de Francisco Alves, Ensino Básico Mediatizado, EBM, 1993. Música: "una Casa Portuguesa”, por Amalia Rodrigues. [s.i.]: Cinematografia Portuguesa, 1993,(15 min.), son., color., Disponível em: <https:// www.youtube.com/watch?v=ndfWzNEKV7E>, Acesso em: 01 jun. 2015. 